This item was submitted to Loughborough's Research Repository by the author.

Items in Figshare are protected by copyright, with all rights reserved, unless otherwise indicated.

\title{
Bus use in a developing world city: implications for the health and well-being of older passengers
}

PLEASE CITE THE PUBLISHED VERSION

http://dx.doi.org/10.1016/j.jth.2015.04.001

PUBLISHER

(C) Elsevier Ltd.

VERSION

AM (Accepted Manuscript)

\section{PUBLISHER STATEMENT}

This work is made available according to the conditions of the Creative Commons Attribution-NonCommercialNoDerivatives 4.0 International (CC BY-NC-ND 4.0) licence. Full details of this licence are available at: https://creativecommons.org/licenses/by-nc-nd/4.0/

\section{LICENCE}

CC BY-NC-ND 4.0

\section{REPOSITORY RECORD}

Aceves-Gonzalez, Carlos, Sharon Cook, and Andrew May. 2015. "Bus Use in a Developing World City: Implications for the Health and Well-being of Older Passengers". Loughborough University. https://hdl.handle.net/2134/17582. 
Bus use in a developing world city

Bus use in a developing world city: Implications for the health and well-being of older passengers

Carlos Aceves-González ${ }^{\mathrm{a}^{*}}$, Sharon Cook ${ }^{\mathrm{a}}$, Andrew May ${ }^{\mathrm{a}}$

${ }^{a}$ Loughborough Design School, Loughborough University, Loughborough LE11 3TU UK

* Corresponding author

C.Aceves-Gonzalez@lboro.ac.uk, Tel +44 (0)1509 226965

S.E.Cook@lboro.ac.uk, Tel +44 (0)1509 226927

A.J.May@lboro.ac.uk, Tel +44 (0)1509 226906

\begin{abstract}
The aim of this article is to investigate the implications of bus use on the health and wellbeing of older passengers in a developing world city. Two complementary methods were used. Twenty-six participants aged 60 and over in Guadalajara, Mexico took part in four focus groups to identify the door-to-door elements of the bus service that impose difficulty in terms of accessing and using it, and their impact on the perceived or actual safety, usability and comfort of older passengers. The second part of the study comprised real time observation of 144 older passengers, to investigate the relationship between the characteristics of the bus service and the observed behaviour of older passengers. The results show that issues such as driver behaviour, features of bus design, crowded buses, pedestrian infrastructure and other passengers' behaviour present difficulty to older passengers who need or want to use the bus service. The existence of these issues presents serious implications for older users in terms of perceived or actual safety, usability and comfort. Given the importance of the role of public transport, the overall conclusion is that there is an urgent need for further improvement of bus services to maintain and promote the health and well-being of older people.
\end{abstract}

Keywords: Older people, Public transport, Health, Well-being, Safety, Usability. 


\section{Bus use in a developing world city: Implications for the health and well- being of older passengers}

\subsection{INTRODUCTION}

\subsection{Context}

The impact of global ageing is expected to be particularly high in developing countries, due to the high rate of population change and limited time to adjust to its impacts (United Nations, 2010). The World Health Organisation claims that 'in all countries, and in developing countries in particular, measures to help older people remain healthy and active are a necessity, not a luxury' (WHO, 2002:6). Transport, and particularly public transport, is one of the services that have been identified in supporting this (WHO, 2007).

A number of studies highlight the benefits, including health and well-being, of continued mobility (Metz, 2000, 2003; Mollenkopf et al., 1997; Mollenkopf et al., 2005; Webber et al., 2010; Yeom et al., 2008). Some studies show that poor transport use can be linked to a reduced health status (Marottoli et al., 2000; Ragland et al., 2005), and this may be worse in developing countries where transport problems are a barrier to older peoples' access to basic social services and participation in local activities (Help the Age International, 2002). Of the transport modes available to older people, public transport, and particularly buses, is one of the most viable options, especially for those who cannot afford a car, or who have ceased driving a car.

Despite the potential benefits of public transport, there are barriers relating to accessibility and use for all passengers, but older and disabled people in particular et al., 2009; Carlsson, 2004). In public transport, safety, ease of use, and comfort are expected attributes in a good service (Balcombe et al., 2004; Molinero and Sanchez, 2005; Redman et al., 2013). In particular, the degree to which people feel safe using public transport has been shown to have a significant effect on their willingness to use these services (WHO, 2007).

\subsection{Approach}

The research was guided by two complementary design approaches - Inclusive Design and Service Design. Inclusive Design 'is a general approach to designing in which designers ensure that their products and services address the needs of the widest possible audience, irrespective of age or ability' (Design Council, 2008). Whilst this is clearly relevant to the design of public transport, it has less presence in developing countries where there is the fastest growing need for the inclusion of older and disabled people. However, it is important to extend the concept of inclusion beyond the physical design of the vehicle since an 'accessible bus' does not necessarily guarantee an 'accessible bus service' (Nickpour et al., 2012:14). The concept of Service Design is an emerging discipline that aims to innovate or improve services that are useful, usable and desirable from the user perspective, and efficient, effective and different from the organisation's perspective (Mager and Sung, 2011; Moritz, 2005). Service Design also considers the user experience based on the full customer journey, during all stages of a user's interaction with the service (Mager and Sung, 2011). Integrating an inclusive perspective with consideration of the full customer journey experience (defined within this study as 'door-to-door' representing from door of origin to door of destination), and the influence of the multiple transport stakeholders, will enable a more complete 
understanding of the safety, comfort and usability barriers to wider uptake of public transport by the older population within a developing country.

\subsection{Aim and objectives}

The overall aim of the paper is to identify, from a passenger perspective, the issues that prevent widespread uptake of the bus transport system by older passengers in a developing world city. Little research has been undertaken in this context and given its potential significance in relation to the rapidly ageing demographic of such countries and the importance of mobility in supporting health and well-being within the older population, the research has the potential to tackle significant real world issues.

The research takes a passenger-focussed stance, identifying factors of relevance from the standpoint of older passengers. The specific objectives of this study are to collect data on what older passengers say, and what older passengers actually do, in relation to bus transport. These data are then interpreted in terms of causality in order to identify whether and how the bus service presents problems from an older passenger perspective, and the implications these may have for passenger health and well-being.

\subsection{METHODS AND MATERIALS}

\subsection{Overview}

The research was undertaken in Guadalajara, Mexico, where there is a high dependency on the private car use due to the lack of an adequate public transport system. The lack of a strong regulatory and legislative regime allows the existence of an informal bus service organization that comprises operators who have their own bus(es) and work in competition with others. Bus drivers are paid by the number of collected passengers, and so they compete, race and 'fight' with other bus drivers (Aceves-Gonzalez et al. 2014). Participants in this study were drawn from the local population who were users of the bus service.

The main methods frequently employed in research of this nature are focus groups, interviews and surveys, with a few studies employing more than one method. Focus groups were selected for use in this research since they enable exploration across a wide range of issues using a large number of participants. In the context of this study, this method would enable the full breadth of the door-to-door experiences of bus use to be captured from a large number of older bus users. Focus groups are also an appropriate mechanism for exploratory data collection but additional care is needed when used with older participants e.g. it is very important to ensure that one person speaks at a time since dividing attention across different sources is more challenging for older people (Barrett and Kirk, 2000). However an inherent limitation of focus groups is uncertainty over the accuracy of the participants' reporting and thus, in this study, this method was complemented by direct observations of passengers on buses. In addition to the potential for a large number of observations over key parts of the service, this method's merits were that it would enable comparison with the focus group findings as well as provide the opportunity to identify factors which the focus group participants may have failed to report.

The proposed methods were submitted for review by the Ethics Committee at Loughborough University. Given that the activities required within the methods were unlikely to pose additional hazards in excess of those the participants would encounter in daily living, no significant amendments were required to the proposed research programme. 


\subsection{Focus groups}

The aim of the focus groups was to understand the problematic issues for older passengers when using local bus transport and the impact of these on their experience of the service. The specific objectives of this data collection were to:

- Identify which elements of the transport system impose significant difficulty in terms of accessing and using the bus service.

- Prioritise those issues in terms of the level of difficulty they pose.

- Identify the impact of these problematic elements on the perceived or actual safety, usability and comfort of older passengers.

The first part of the study used a structured format of focus groups to understand and prioritize issues that impose difficulties for older passengers using the bus service. This was achieved through facilitated group discussion structured around the elements of the bus service identified in the literature, such as information (routes, bus stop locations, existence and design of maps and timetables), driver behaviour (kindness, driving style and the time they allow for passengers boarding and alighting), and bus design (size and shapes of steps, handrails location, and seats). These elements, which are common to bus service provision in most countries, were then ranked using a card sorting activity. Participants were invited to identify any additional elements which reflected their particular context of use and include these within the card sorting activity.

Participant recruitment was undertaken through the Metropolitan Centre of the Elderly, a local day centre. Twenty-six older people were selected based on being aged 60 or over with sufficient language and cognitive abilities to allow them to provide informed consent and participate actively in the group discussions. Four focus groups were conducted, within the participants' routine visit, as shown in Table 1 . The aim was to recruit a varied sample in terms of gender and travel habits, within the constraints imposed by the target group. A questionnaire was used to capture the participants' demographic data, travel habits and levels of difficulty undertaking specific aspects of bus travel.

\begin{tabular}{ccclc}
\hline $\begin{array}{c}\text { Focus } \\
\text { group }\end{array}$ & Gender & Age & Passengers type & $\begin{array}{c}\text { Participants who reported } \\
\text { mobility problems }\end{array}$ \\
\hline 1 & 2 male, 5 female & $64-75$ & Frequent bus users & 3 \\
2 & 6 female & $60-77$ & Frequent bus users & 5 \\
3 & 2 male, 5 female & $62-76$ & Frequent bus users & 1 \\
4 & 5 male, 1 female & $64-75$ & Infrequent bus users & 3 \\
\hline
\end{tabular}

Table 1: Focus group characteristics

All focus groups were recorded and transcribed in full. These files were imported into NVivo (QSR International). Based on the concepts of the elements of the bus service, and the concepts of usability, safety and comfort, a theoretically driven thematic analysis was used (Braun and Clarke, 2006; Robson, 2011). The analysis was undertaken at a semantic and realistic level (Braun and Clarke, 2006), i.e. themes, subthemes and codes were identified within the explicit meaning of the data. Initial themes were based around (1) the problematic issues and (2) their impact on the passenger. These were derived initially from the theoretical perspectives, and then developed based on participant discussion. 


\subsection{Observations}

The second part of the study comprised passenger observations, their aim being to investigate the relationship between the characteristics of the bus service and the behaviour of older passengers. In addition, the observations were undertaken to provide evidence that could be used to support or refute the findings of the focus groups within this study, i.e. to enable triangulation of data by comparing what the participants in this study said they did, with what (a separate group of) older passengers were actually observed to do.

The specific objectives of the passenger observations were to:

- Understand how older bus passengers behaved when they got on buses, travelled on them and got off them.

- Identify observed impacts on passenger safety, usability and comfort.

- Enable comparison of stated (focus groups) and observed limitations of the current bus service.

Data were collected from 144 passengers during 49 observational sessions over four weeks, comprising 17 different urban bus routes running between the north-western and the eastern outskirts of Guadalajara, crossing the city centre and hence having heavy passenger flow. All data were collected between 7am and 8pm on weekdays The observer took a seat in the middle of the bus in order to have an overview of the entire bus. The driver and passengers were unaware of the presence of the experimenter, or that the study was taking place, but permission to undertake the study had been obtained from the head of the bus operator. (Note that buses were typically privately owned, even though there were organisations overseeing their operation.) An A5 sized record sheet was used to record details for each observed passenger. This sheet comprised a set of data fields based on the data framework shown in Figure 1.

Data were collected as soon as the passenger stepped onto the bus and observations continued until they stepped off the bus. To ensure accurate data capture (especially when the buses were crowded), only three passengers at any one time were observed - as one passenger alighted, observation continued with the next older passenger that boarded the bus. The judgement of a passenger as 'older' was necessarily subjective based on an appearance of being 60 plus, but in the majority of cases qualifying age was indicated by the use of a concessionary payment pass by the passenger. The concessionary pass can be obtained, on application, by people aged 60 or more.

Observational data were recorded by journey stage: boarding the bus, making payment, moving to a seat, travelling and alighting. Boarding time was defined as the time from the driver opening the door for passengers, until that passenger was seated or had moved to their final standing position. During the payment process it was recorded whether the passenger used a concessionary pass, whether there were any observed difficulties during the payment process, and the general behaviour of the driver. Once the passenger had boarded, it was recorded whether there was any visual indication of a loss of balance from the passenger. These were based on the protective responses to a potential or actual loss of balance (Maki and McIlroy, 1997; Redfern et al., 2001), but within the constraints of the study, were interpreted as the taking of compensatory actions to control their posture or stability such as steps after stumbling, arm swings, and grasping the handrail etc. The seat that the passenger sat in was recorded, as was any movement to a different seat during the journey (for example one nearer the exit to aid alighting). Alighting time was recorded from the point at which the passenger stood up from their seat, until they had finished descending the steps of the bus. 
Since the buses varied in design, relevant features of the bus design were captured, such as the interior and seat layout, type of transmission, presence of handrails, the location and height of exit bells and the design of the steps on entrance and exit. Other details were noted when relevant, such as the general road conditions, and the behaviour of other passengers such as younger passengers occupying the priority seats reserved for older passengers.

\begin{tabular}{|c|c|c|c|}
\hline & \multicolumn{3}{|c|}{ Stage of journey } \\
\hline & Boarding & Travelling & Alighting \\
\hline $\begin{array}{l}\text { Coded } \\
\text { Passengers' } \\
\text { behaviour } \\
\text { by stage }\end{array}$ & $\begin{array}{l}\text { 1. Climbing steps } \\
\text { 2. Gripping handrails } \\
\text { 3. Losing balance } \\
\text { 4. Moving to a seat } \\
\text { 5. Time for boarding }\end{array}$ & $\begin{array}{l}\text { 6. Traveling standing } \\
\text { or seated } \\
\text { 7. Using a priority } \\
\text { seat } \\
\text { 8. Chosen seat or } \\
\text { place to travel }\end{array}$ & $\begin{array}{l}\text { 9. Standing up } \\
\text { 10. Moving to the exit } \\
\text { door } \\
\text { 11. Used door to } \\
\text { exit } \\
\text { 12. Descending steps } \\
\text { and alighting } \\
\text { 13. Time for alighting }\end{array}$ \\
\hline $\begin{array}{l}\text { Bus service } \\
\text { characteristics } \\
\text { (at any stage) }\end{array}$ & \multicolumn{3}{|c|}{$\begin{array}{c}\text { Crowded buses, smooth or unsteady trips } \\
\text { Driving style, drivers' attitudes and behaviour } \\
\text { Bus design, entrance, steps, seats, use of handrails, gangway, bell }\end{array}$} \\
\hline $\begin{array}{l}\text { External factors } \\
\text { (at any stage) }\end{array}$ & \multicolumn{3}{|c|}{$\begin{array}{c}\text { Bus service infrastructure, roads, bus stops, pavements } \\
\text { Other road users, traffic }\end{array}$} \\
\hline
\end{tabular}

Fig 1 Observation framework used for data collection

\subsection{RESULTS}

The section below presents results relating to the focus groups and passenger observation that are described in Section 2.

\subsection{Focus groups}

\subsubsection{Sample demographics}

A total of 26 participants took part in four focus groups. The majority were female (65\%) and frequent passengers (77\%). About half (11/26) of the participants reported having physical problems which limited their mobility. Table 2 summarises the participant demographics. 


\begin{tabular}{llc}
\hline Variable & & \\
\hline Age & Mean (min-max) & $69.7(60 / 77)$ \\
\hline Gender & Male & 9 \\
& Female & 17 \\
\hline Living situation & Alone & 4 \\
& With partner & 10 \\
& With partner and children & 10 \\
& Other & 2 \\
\hline Problems limiting & Yes & 11 \\
mobility & No & 15 \\
\hline Employment status & Employee & 1 \\
& Retired & 13 \\
& Self-employed & 3 \\
& Not working (not retired) & 9 \\
\hline Main source of & Employment & 1 \\
income & Pension & 13 \\
& Own business & 2 \\
& Financial help from relatives & 9 \\
& Other & 1 \\
\hline Monthly income & Less than \$3,500.00 & 21 \\
(Mexican pesos) & \$3,501.00 and \$7000.00 & 4 \\
& \$7001.00 and \$ 10,500.00 & 0 \\
& More than \$10,500.00 & 1 \\
\hline
\end{tabular}

Table 2 Participants' characteristics $(n=26)$

\subsubsection{Travel habits}

A general overview of participants' travel habits using the public transport system is shown in Table 3. For most participants, the bus service was the most usual mode of transport, and where passengers stated they used the bus service during the morning peak periods, this included periods where they were required to (e.g. for medical appointments) rather than choosing to do so. The table indicates that the main reason for using the bus was directly related to health purposes for these older users.

\begin{tabular}{lccc}
\hline $\begin{array}{l}\text { Reason to use the bus } \\
\text { service }\end{array}$ & Number & Average Frequency & Time of the day \\
\hline Medical services & 16 & Monthly & Morning \\
Shopping & 14 & Weekly & Afternoon \\
Visit friends or family & 11 & Monthly & Morning \\
Banking & 6 & Fortnightly & Afternoon \\
Attending clubs or associations & 5 & 2 or 3 times per week & Morning \\
Work & 4 & 2 or 3 times per week & Morning \\
\hline
\end{tabular}

Table 3 Travel habits of participants $(n=26)$

\subsubsection{Prioritisation of problematic issues}

An objective in this study was to investigate which bus travel issues have the greatest impact on bus use by the older passengers. Based on the initial card sorting activity in the focus groups, an aggregated ranking was produced based on the prioritization of issues by all participants; no additional elements were raised. Table 4 shows the ranking given to each issue. 


\begin{tabular}{cll}
\hline Ranking & Problematic issues & Reasons for stating the issue \\
\hline $\mathbf{1}$ & Drivers & Unfriendly drivers \\
& & Lack of consideration towards older people \\
& Large gap between bus and kerbside \\
& Reluctance to pick up older passengers \\
& & Allowing inadequate time to board and alight \\
& & Driving too fast and unsteadily \\
& & Entry/exit steps too high \\
$\mathbf{2}$ & Bus design & Steps with irregular shape \\
& & No or inappropriately placed handrails \\
& & Narrow gangway between seats \\
& & Limited number of priority seats \\
& & Difficulties in using the bus due to crowding \\
$\mathbf{3}$ & Crowded buses & Insufficient number of seats \\
& & Having to travel standing \\
& & Long distance to nearest bus stop \\
$\mathbf{4}$ & Walking distances & Poor pavement conditions with obstructions \\
& & Problems crossing roads due to heavy traffic \\
& & Lack of pedestrian crossings \\
& & Physical difficulties due to standing while waiting \\
$\mathbf{5}$ & Waiting time & Unreliable service and lack of timetables \\
& & No information about routes or route changes \\
$\mathbf{6}$ & Information & Drivers unwilling to offer discounted (half price) \\
$\mathbf{7}$ & Payment method & fares to older passengers \\
& & Lack of routes matching preferred destinations \\
$\mathbf{8}$ & Routes &
\end{tabular}

Table 4 Participant ranking of issues related to bus use

\subsubsection{Problematic issues and their impact on older passenger experience}

Based on the thematic analysis of the focus group discussions, two themes (problematic issues and impact on user's experience) and 13 sub-themes were identified. Figure 2 illustrates these sub-themes and how problematic issues are related to the user's experience in terms of perceived or actual safety, usability problems, comfort, and perceived security. In fact about half of the participants (11) stated that they had actually been injured as a direct result of using the bus, hence bus use has the potential to directly impact the health of older passengers.

In the figure, the subthemes relating to issues and experience are arranged by frequency, with the percentage (in parentheses) of participants who raised that specific concern. For example, all participants raised issues to do with drivers, and all also identified perceived or actual safety implications.

Based on the descriptions given by participants, the figure also shows (lines with arrows) how each aspect of the user's experience was influenced directly by one or more of the issues identified. The darker lines show where a third of participants (9) stated a specific causal link between an issue and a passenger impact. Thus, the main problematic issues have a strong direct link with safety and usability problems. 


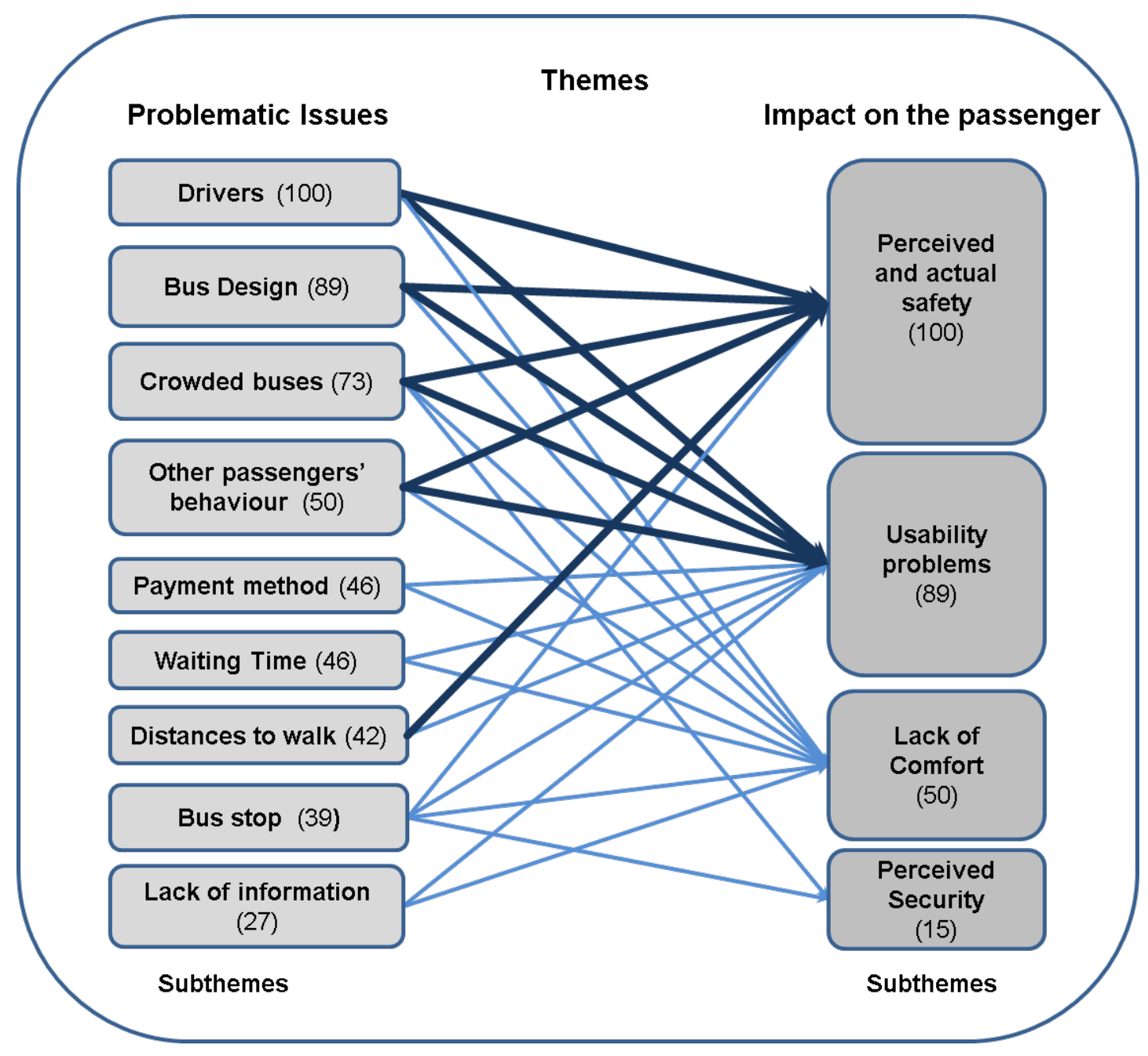

Fig 2 Problematic issues and their impact on older passenger experience

\subsection{Data analysis and results of the observational study}

Results from the observational method are presented in four sections; the first section presents observations on the characteristics of the bus service (bus design, trip, and driver behaviour); the subsequent three sections describe the observed behaviour of the passengers during the stages of boarding the bus, traveling on the bus, and alighting from the bus.

\subsubsection{Observations on the bus service}

\section{Bus design}

Although there are four or five different types of buses in common use throughout the city, all of them shared similar characteristics. Buses were single deck built on truck chassis; therefore, all of them had up to four steps to enter and exit the bus. The height of the first step was 40 centimetres, and the rest of steps varied from 23 to 28 centimetres, which is above of the recommended dimensions of 150-200 mm (Petzäll, 1993). Figure 3 shows some examples of the external appearance of these buses. 

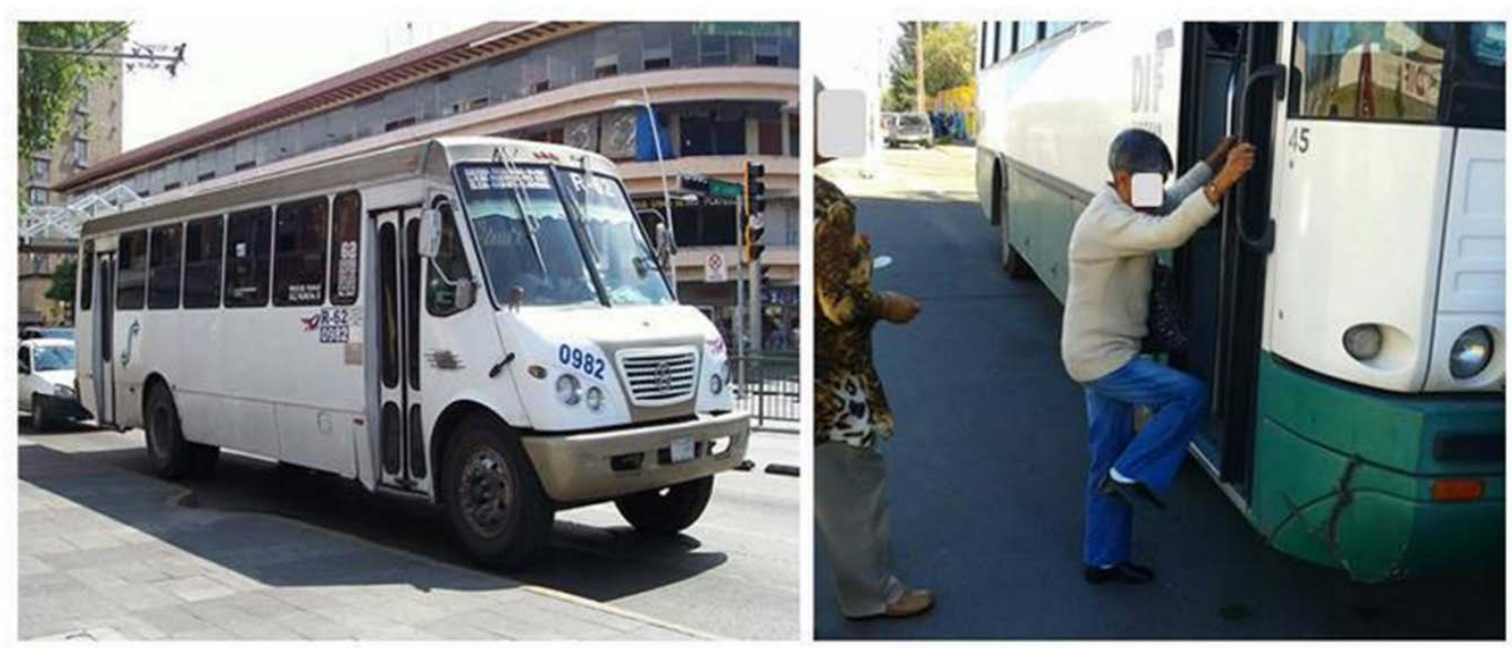

Fig 3 The buses were built on converted truck chassis

Due to buses being built on truck chassis, they all had high passenger platforms, no ability to lower the floor of the bus, and manual transmission. The handrails were generally placed horizontally on both sides of the gangway at a height of approximately of 175 centimetres. There were vertical handrails only near to the front and rear door. Most of the buses had a single bell placed on the vertical handrail close to the rear door at a height of approximately of 170 centimetres. The buses were designed so that passengers boarded at the front door and exited through the rear.

\section{Characterisation of the observed journeys}

Crowded buses were common during the observational sessions, to the extent that not only were there no seats available, but that there were so many standing passengers that it was difficult to board and alight the bus, and move through the bus. The degree of crowding depended on the time of the day (e.g. mornings between 7.00 to 9.30, afternoon from 12.30 to 14.30, and evenings from 17.00 to 19.00), but buses were also overcrowded when they were near to significant areas of the city such as the city centre, hospitals, governmental offices, and markets. The road surface was mixed, with some areas being recently re-surfaced, but the majority of roads were in poor condition. Overall it was possible to observe that of the journeys relating to the observed passengers, only $14 \%$ of them were considered as 'smooth' journeys over their entirety. The remaining journeys had at least some sections of bus instability, and of these, approximately $60 \%$ had frequent and extended sections where passenger instability was observed.

\section{Drivers' behaviour}

It was observed in at least $50 \%$ of the trips that the driving style employed included frequent acceleration and deceleration and sharp braking. This was exacerbated by the frequent gear changes required with the manual gear boxes and the suspension design of the converted truck chassis. The road conditions were often poor and drivers generally observed a lack of caution when passing over speed bumps or potholes. The actions of the drivers indicated they were driving under time pressure. In only approximately $10 \%$ of cases drivers were observed to be driving more cautiously, as is typical within the bus transport system in the developed world. 
It was observed that the drivers usually did not stop near to the kerb when picking up or dropping off passengers. However, this was not always the decision of the driver, due to passengers waiting in the road, a lack of official bus stops or even pavements, and cars parked at or near to the bus stops which made it impossible to stop the bus adjacent to the pavement. On occasions the drivers did not actually stop and only slowed down sufficiently to allow passengers to get on or off - in these cases passengers were forced to actually jump on or off the bus. Drivers tended to pressure passengers into boarding or alighting the bus quickly, by calling out commands to 'hurry up'. Similarly, it was noted that some drivers did not actually stop to collect passengers or allow them to alight at a designated bus stop. These behaviours were mainly observed when the bus was crowded or when the driver appeared to be under particular time pressure.

It was recorded that drivers consistently drove off before the passengers were seated. In fact, the most common behaviour was that the drivers drove away from the stop whilst the last boarding passenger was still on the first step, and even before they had presented payment for the journey. This behaviour was observed in $79 \%$ of the observed journeys; the exceptions being situations where passengers boarded at a bus stop located at a junction controlled by traffic lights (and it was at a red light), or when there were more passengers boarding, and consequently the driver was required to wait before driving off.

Drivers also demonstrated a tendency to cram as many passengers as possible in the bus, even when the bus was already crowded. Some other driver behaviours were observed less frequently. During the less-crowded times on the bus, it was possible to observe, based upon body gestures, that on occasions drivers made no direct eye contact with the passengers and were abrupt and discourteous during the payment process. In addition, they sometimes did not allow passengers to alight from the front door (see below).

\subsubsection{Observed passengers' behaviour - Boarding stage}

Boarding the bus commenced with the passengers climbing the steps at the front of the bus. All the observed passengers were physically able to complete this task, but with varying degrees of difficulty. Many of them climbed the steps placing both feet on each step, and also pulled themselves up using the handrails in order to overcome the step height (particularly the first one which was typically about $40 \mathrm{~cm}$ high) or to maintain their posture and balance. It was noted that the observed boarding behaviour varied according to the ability of passengers, size of steps, and whether the passenger was stepping up from the level of the road or from a raised pavement.

Over $60 \%$ of older passengers were seen to lose their balance when they were boarding the bus. This loss of balance occurred mainly when passengers were paying the driver or when moving to a seat. It was observed that passengers had trouble getting cash from their wallets, handling the cash, as well as grasping the handrails and holding their belongings at the same time. Some older passengers employed alternative practices such as placing their belongings at the floor while they were paying or taking a seat before paying. However, the main reason for passengers losing their balance during boarding was the fact that the drivers drove off before passengers were seated.

An analysis was also undertaken of the time taken to board the bus. Figure 4 shows a frequency distribution of the boarding and alighting times, as defined in Section 2.3. For the boarding times, it can be seen that the typical time for boarding was between 15 and 35 seconds, although there were instance of much longer durations as a result of the difficulty passengers faced in moving through a crowded bus in order to take a seat. 

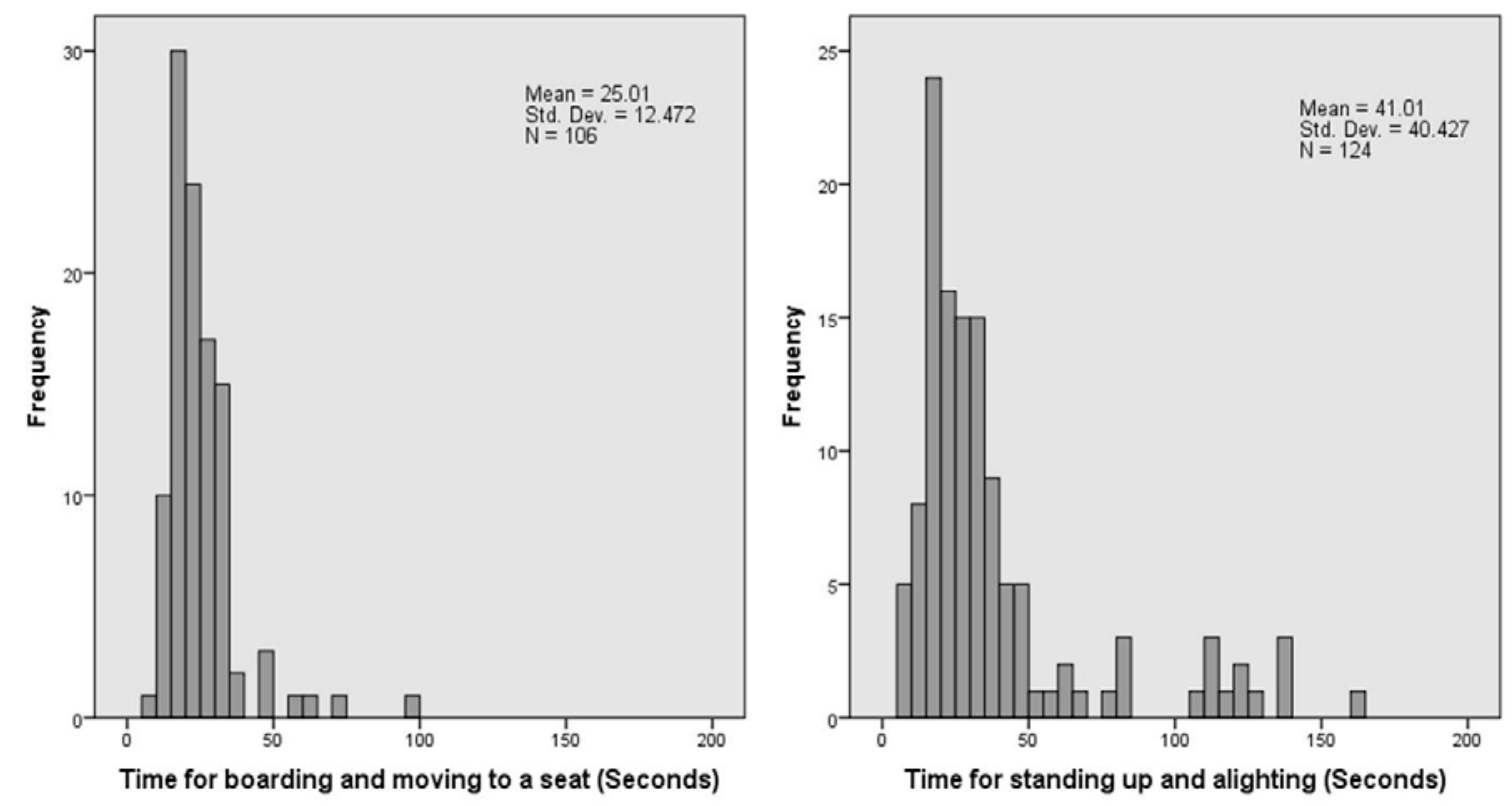

Fig 4 Frequency distribution of boarding and lighting durations

\subsubsection{Observed passengers' behaviour - Travelling stage}

The data relating to this stage included whether older passengers were traveling standing or seated, and the location they chose to travel inside the bus. For this analysis the passenger locations were categorised as seating in the front, middle or rear of the bus, plus those traveling standing. The data are as follows: $62 \%$ were seated in the front of the bus; $17 \%$ were seated in the mid-section of the bus; $6 \%$ were seated in the rear of the bus; $15 \%$ were required to stand due to lack of available seating. In total $47 \%$ of observed participants used one of the priority seats which were located at the front of the bus (typically the first two rows). In 33\% of observed passenger journeys, a younger passenger without visual indication of disability was occupying a priority seat when that older passenger was boarding the bus.

\subsubsection{Observed passengers' behaviour - Alighting stage}

\section{Standing up and moving to the exit door}

It was generally observed that all passengers (and not just the older passengers) had to stand up before the bus had stopped in order to ring the single 'stop' bell and to reach the exit doors. The older passengers anticipated their alighting by standing up out of their seat and moving toward the exit door in advance of the stop they were alighting from. In fact, it was observed that many of them stood up at the previous bus stop, when the bus was stationary, in order to walk through the bus and reach the bell or to ask the driver to stop at the following bus stop.

\section{Preferred door to exit}

The buses were designed such that passengers boarded at the front of the bus by the driver, and were required to exit at the rear door. However, it was noted that $81 \%$ of the observed participants used the front door to alight from the bus. Many of the older participants in the focus group study expressed a preference to use the front door for alighting because they did not feel safe using the back door. They believed that drivers were not able to observe them in this location and would drive off before they had descended to ground level and were clear of the bus. 


\section{Exiting the bus}

It was noted that the older users had considerable difficulty in actually exiting from the buses. Many of them placed two feet on each step, tightly held the handrails, and descending slowly (whilst being under pressure to alight as quickly as possible). A common pattern of behaviour was for passengers to pause before descending the last step, especially when driver had stopped far from the kerb and the passengers could not step easily onto the pavement (and sometimes had to physically jump off the bus). Indeed on at least fourteen occasions it was observed that older passengers had to turn round and descend backwards in order to be able to negotiate the final step off the bus.

As for boarding the bus, an analysis was also undertaken of the time taken to alight from the bus, as defined in Section 2.3. It can be seen in Figure 4 above that the typical alighting time was between 15 and 50 seconds, but with a greater proportion of longer durations than seen in the distribution for boarding times.

\subsection{DISCUSSION}

\subsection{Older passengers and reasons for bus use}

This research has focussed on investigating the implications of bus use, in a developing world city, on the health and well-being of older passengers. Table 2 indicates that most of the participants (21) in the focus group study reported a monthly income of less than $\$ 3500.00$ MXN (about 160.00 GBP) which suggests that many older passengers may use the bus service due to 'need' rather than 'choice' since they may not be able to afford alternatives such as running a car or using taxis. Table 3 shows the importance of the bus service in supporting the health and well-being needs of older people within the city; the main reason for using the bus was to access medical services (health) followed by shopping, visiting family and friends and participating in social activities (well-being).

\subsection{The door-to-door passenger experience}

However the research identifies a wide variety of problematic issues relating to bus service use that affect older passengers in terms of safety, usability and comfort and these in turn have implications for their health and well-being. Through the combined use of focus groups and observations, problems were identified over the whole of the passengers' door-to-door journey with the key issues relating to: bus drivers' behaviour, poor bus design, crowded buses, other passengers' behaviour, and those problems that older people face as pedestrians. This total journey process is illustrated in Figure 1 which shows that the impact on the older users' experience is not due to isolated factors, but rather by a combination of them. Thus, each part of the process for using the bus service involves a series of different problematic issues for older passengers, e.g. difficulties in boarding the bus might comprise: the lack of bus stop or pavement (bus stop and pavements); if driver wants to collect the passenger or not (driver behaviour); if the driver stops the bus near to the kerb (driver behaviour), if not, then the passenger has to ascend the first step from the ground which is $40 \mathrm{cms}$ (bus design); the passenger feels compelled to board quickly because the bus driver seems to be hurry (driver behaviour and service operation); the passenger then climbs the rest of the stairs, pays the driver and moves to a seat, in the absence of well-designed handrails (bus design), while the driver has driven off since passenger was on the first step potentially destabilising the passenger (driver behaviour and service operation).

Although, most of these issues have been reported as barriers to using the bus service (Broome et al., 2009), much of this research has been undertaken in developed countries 
where the existence of regulatory and legislative regimes encourages the transport operators to provide an inclusive transport service. Conversely, in developing countries which often lack such requirements, such barriers are more widespread (WHO, 2007) and their impacts can be more severe. Results suggest that such is the case of the bus service in Guadalajara, Mexico.

\subsection{Health and well-being impacts}

When considering the impacts of all of these problems across the whole customer journey, aspects relating to actual and perceived safety predominate. An example of such concerns can be illustrated in relation to boarding the bus where climbing a potentially high first step and ascending further steps under a time pressure followed by the driver driving off before passenger is seated represents a potential injury risk for older passengers since they are less stable and do not respond as well as younger people to postural perturbation (Maki and McIlroy, 1996; Startzell et al. 2000). Results from the observational study found that a high percentage of older passengers lost their balance while they were boarding the bus and moving to a seat. This may be why all the participants in the focus groups raised concerns over being physically hurt at some stage whilst using the bus service. These findings indicate that the bus service, through vehicle design and driver behaviour, has the potential to reduce passenger safety by causing loss of balance which can lead to older passengers falling and so potentially negatively impact their health.

However it is not just the falls themselves, but the fear of falling which is important when considering older passengers. This fear combined with poor usability and a lack of comfort may limit older peoples' ability and willingness to engage with the bus service. Based on the Maslow's hierarchy of needs model (Maslow, 1987), some authors as Jordan (2002) and Bonapace (2002) have developed similar models to understand users' needs for using products. Particularly useful for this study is Bonapace's Model, which proposes a four-level model with 'safety and well-being' at the lowest level, followed by functionality, usability, and pleasure at the top. Using this model to analyse and interpret the current results, it can be inferred that older participants expressed less concern regarding the impact on their comfort (which could be considered as 'pleasure' in the Bonapace's Model) because they were mainly concerned for their own safety (safety and well-being), and for the difficulties of using the service (usability).

What the data are suggesting is that the health and well-being benefits to be obtained from the bus service, in terms of accessing health services, shopping, visiting family and friends and participating in social activities, are not yet being maximised. Achieving this may be hampered in some developing countries by: a highly fragmented service provider market comprising a large number of competing owner operators opposed to a smaller number of operating companies, a lack of accessibility regulations, poorly designed vehicles and poor driver training . In addition, it is worth noting that the results of the study are based on data from both frequent and infrequent bus users in the focus groups, and observations of actual passengers. However potential insights into additional health and well-being benefits may have been gained from incorporating non bus users within the focus groups, including those who are no longer able to use the service, those who were never able to use the service and those who chose not to.

\subsection{Contrast between methods}

A major strength of this study was the use of two methods which enabled the researchers to compare and contrast what participants reported within the focus groups with what (a 
different set of) passengers were observed doing, as well as investigate the characteristics of the service that participants reported as problematic. Whilst there were several findings based on the two methods of data collection that supported each other e.g. the issues relating to steps height and crowded buses, there were also some notable differences in the results. For instance, with respect to how the passengers attributed poor service quality and the root causes in the focus groups, drivers were blamed for the instability of the trip. However whilst the stability of a trip depends on vehicle acceleration or deceleration, which is determined mainly by the driver's driving skills (Karekla and Tyler, 2012), it was also noted through the observations that trip instability was also affected by the bus design (manual transmission and rigid suspension) and the road surface conditions (uneven roads or with potholes).

\subsection{CONCLUSIONS}

The overall aim of the paper was to identify the issues that prevent widespread uptake of the bus transport system by older passengers in a developing world city, focussing on a health and well-being perspective. This study found that there are problematic issues, from 'door-todoor' that pose difficulties for older people wishing to use the bus service. Data from passenger observation and from the focus groups resulted in similar findings. The three main problem areas were the attitudes and behaviours of the drivers, the design of the buses (which were based on converted truck chassis), and the high levels of overcrowding. These factors and others presented perceived and actual risks to the accessibility and usability of the bus transport system, and to the safety and comfort of older passengers. Taken together, it has been shown that these factors make travelling by bus problematic for older passengers as well as more hazardous given the potential for falls. The design of the bus service can thus be seen to impact health and well-being in a number of ways - directly, through falls and through its linkage to medical services and indirectly through the ongoing physical and psychological challenges posed by its use and by its importance to a person's mobility beyond the home. The overall conclusion from this study is that much work can be done to improve the bus transport system in developing world cities with the characteristics of Guadalajara covering bus design, driver training and infrastructure provision. In addition, measures in place in other countries may also offer benefits e.g. travel training to support those who are less able or less inclined to travel independently (AECOM, 2011) and also regulatory control which may provide the necessary mechanism for incentivising drivers to prioritise the needs of older passengers above their need to compete for passenger fares. Taken as a whole, such efforts have the potential to impact positively on the health and wellbeing of the older population.

\section{ACKNOWLEGMENTS}

This research project was supported by the Ministry of Public Education of Mexico through the Program of Improvement of the Professors, PROMEP/1 03.5/1 0/5397. 
Bus use in a developing world city

\section{REFERENCES}

Aceves-Gonzalez, C., Cook, S., May, A. 2014. Inclusive service design: In search of better services. In Soares, M., Rebelo, F. (Eds.), Advances in Ergonomics in Design, Usability \& Special Populations. Part III (pp. 10-19). United States of America: Published by AHFE Conference (C) 2014.

AECOM 2011. Travel training - Good paractice guide. Department for Transport report. Retreived from https://www.gov.uk/government/uploads/system/uploads/attachment_data/file/4482/guid ance.pdf

Balcombe, R., Mackett, R., Paulley, N., Preston, J., Shires, J., Itheridge, H., Wardman, M., White, P. 2004. The demand for public transport: A practical guide, TRL Report. Crowthorne,UK.: TRL 593.

Barrett, J., Kirk, S. 2000. Running focus groups with elderly and disabled elderly participants. Applied Ergonomics, 31(6), 621-629.

Bonapace, L. 2002. Linking Product Properties to Pleasure: The Sensorial Quality Assessment Method - SEQUAM. In Green, W. S., Jordan, P. (Eds.), Pleasure With Products: Beyond Usability (pp. 189-217). London: Taylor \& Francis.

Braun, V., Clarke, V. 2006. Using thematic analysis in psychology. Qualitative Research in Psychology, 3(2), 77-101. doi:10.1191/1478088706qp063oa

Broome, K., McKenna, K., Fleming, J., Worrall, L. 2009. Bus use and older people: A literature review applying the Person-Environment-Occupation model in macro practice. Scandinavian Journal of Occupational Therapy, 16(1), 3-12. doi:10.1080/11038120802326222

Carlsson, G. 2004. Travelling by urban public transport: Exploration of usability problems in a travel chain perspective. Scandinavian Journal of Occupational Therapy, 11(2), 78-89. doi:10.1080/11038120410020548

Design Council. 2008. Inclusive Design Education Resource. London: Design Council. Retrieved from http://www.designcouncil.info/inclusivedesignresource/index.html

Help Age International. 2002. Gender and transport for older people. Retrieved from http://www.helpage.org/silo/files/gender-and-transport-for-older-people.pdf

Jordan, P. 2002. Designing Pleasurable Products: An Introduction to the New Human Factors. London: Taylor \& Francis.

Karekla, X., Tyler, N. 2012. Sustainable Bus Design Focused on Improved Accessibility. In transed2012. Retrieved from http://www.transed2012.in/Common/Uploads/Theme_E_Session_3/transedAbstract0021 4.pdf 
Mager, B., Sung, T. 2011. Special issue editorial: Designing for services. International Journal of Design, 5(2), 2-4.

Maki, B., McIlroy, W. 1996. Postural control in the older adult. Clinics in Geriatric Medicine, 12(4), 635-658.

Maki, B., McIlroy, W. 1997. The role of limb movements in maintaining upright stance: The “change-in-support” strategy. Physical Therapy, 77(5), 488-507.

Marottoli, R., Mendes de Leon, C., Glass, T., Williams, C., Cooney, L., Berkman, L. 2000. Consequences of driving cessation: Decreased out-of-home activity levels. Journal of Gerontology: Social Sciences, 55B(6), S334-S340.

Maslow, A. 1987. Motivation and Personality (3rd Edition). New York: Addison-Wesley Educational Publishers.

Metz, D. 2000. Mobility of older people and their quality of life. Transport Policy, 7(2), 149152. doi:10.1016/S0967-070X(00)00004-4

Metz, D. 2003. Transport policy for an ageing population. Transport Reviews, 23(4), 375386. doi:10.1080/0144164032000048573

Molinero, A., Sanchez, L. 2005. Transporte Público: Planeación, Diseño, Operación y Administración (1st reprint). Mexico: Publicaciones UAEM.

Mollenkopf, H., Marcellini, F., Rouppila, I., Szeman, Z., Tacken, M. 2005. Enhancing mobility in later life: Personal coping, environmental resources and technical support; the out-of-home mobility of older adults in urban and rural regions of five European countries. Amsterdam: The Netherlands: IOS Press.

Mollenkopf, H., Marcellini, F., Ruoppila, I., Flaschenträger, P., Gagliardi, C., Spazzafumo, L. 1997. Outdoor mobility and social relationships of elderly people. Archives of Gerontology and Geriatrics, 24(3), 295-310.

Moritz, S. 2005. Service Design. Practical Access to an Evolving Field. London.

Nickpour, F., Jordan, P., Dong, H. 2012. Inclusive Bus Travel - A Psychosocial Approach. In Langdon, P., Clarkson, J., Robinson, P., Lazar, J. Heylighen, A. (Eds.), Designing Inclusive Systems (pp. 13-23). London: Springer London. doi:10.1007/978-1-44712867-0

Petzäll, J. 1993. Ambulant disabled persons using buses: Experiments with entrances and seats. Applied Ergonomics, 24(5), 313-326.

Ragland, D., Satariano, W., MacLeod, K. 2005. Driving cessation and increased depressive symptoms. Journal of Gerontology: Medical Sciences, 60A(3), 399-403.

Redfern, M., Cham, R., Gielo-Perczak, K., Grönqvist, R., Hirvonen, M., Lanshammar, H., Marpet, M., Pai, C, Powers, C. 2001. Biomechanics of slips. Ergonomics, 44(13), 113866. doi:10.1080/00140130110085547 
Bus use in a developing world city

Redman, L., Friman, M., Gärling, T., Hartig, T. 2013. Quality attributes of public transport that attract car users: A research review. Transport Policy, 25, 119-127. doi:10.1016/j.tranpol.2012.11.005

Robson, C. 2011. Real World Research (3rd Edition). Cornwall, UK: Wiley.

Startzell, J., Owens, D., Mulfinger, L., Cavanagh, P. 2000. Stair negotiation in older people: A review. Journal of the American Geriatrics Society, 48(5), 567-580.

Webber, S., Porter, M., Menec, V. 2010. Mobility in older adults: A comprehensive framework. The Gerontologist, 50(4), 443-50. doi:10.1093/geront/gnq013

WHO. 2002. Active Ageing. A Policy Framework. Geneva: WHO. Retrieved from http://whqlibdoc.who.int/hq/2002/who_nmh_nph_02.8.pdf

WHO. 2007. Global Age-friendly Cities: A Guide. WHO. Retrieved from http://www.who.int/ageing/age_friendly_cities_guide/en/

Yeom, H., Fleury, J., Keller, C. 2008. Risk Factors for Mobility Limitation in CommunityDwelling Older Adults: A Social Ecological Perspective. Geriatric Nursing, 29(2), 133140. doi:10.1016/j.gerinurse.2007.07.002 